\title{
O ENSINO DO CONTRÔLE DA FERTILIDADE E DE PROBLEMAS POPULACIONAIS EM ESCOLAS MEDICAS BRASILEIRAS (1)
}

\begin{abstract}
Yunes, J. - O ensino de contrôle da fertilidade e de problemas populacionais em escolas médicas brasileiras. Rev. Saúde públ., S. Paulo, 4:79-84, jun. 1970.

Resumo - Foi realizada em 1967 uma pesquisa sôbre o ensino do contrôle da fertilidade e de problemas populacionais em 42 escolas médicas brasileiras. Verificou-se, que das 22 escolas médicas que responderam ao questionário, 14 ensinavam o contrôle da fertilidade e 6 expressaram interêsse em iniciar tal ensino. Grande interêsse foi demonstrado nos aspectos sociais e demográficos e grande ênfase foi dada para a indicação do contrôle da fertilidade nos casos de "enfermidade ou agravamentos físicos", assim como para "problemas psiquiátricos". A viabilidade de clínicas para o ensino aos estudantes de medicina em técnicas contraceptivas foi em geral muito baixa. O uso de pílulas anovulatórias e o método do rítmo foram os contraceptivos preferidos para o ensino.
\end{abstract}

\section{MATERIAL E MÉTODO}

Antes do estudo ser realizado, a Organização Panamericana da Saúde (OPS) foi consultada para opinar sôbre a viabilidade e a importância que poderia apresentar tal pesquisa, em uma época em que o assunto era sobejamente discutido. Uma resposta favorável foi dada pela OPS, tendo a mesma fornecido o número e enderêços das escolas médicas brasileiras existentes em $1966^{3}$. Este tipo de estudo foi realizado também para as escolas médicas norte-americanas e latino-americanas ${ }^{1,2,4}$. Porém, apresentaremos sòmen- te os principais resultados fornecidos pelas escolas médicas brasileiras. Para tanto, foi elaborado um questionário e enviado a cada uma das escolas, acompanhado de uma carta dirigida aos seus Diretores bem como aos dirigentes dos departamentos de Obstetrícia e Ginecologia, Medicina Preventiva e Clínica Médica. Para as escolas que não contestaram o questionário, enviou-se, por três vêzes consecutivas, outro exemplar do mesmo, seguido de uma carta explicando a importância que oferecia êste estudo.

Recebido para publicação em 27-2-1970.

(1) Estudo realizado em 1967, durante o Curso para "Master in Public Health", da Escola de Saúde Pública da Universidade de Michigan - Ann Arbor - USA. A publicação dos resultados dêste trabalho deve-se em parte, à ajuda do Dr. Johan W. Eliot, professor da Universidade de Michigan e do Dr. Francisco Villadiego, Médico do Curso de Pós-Graduação em Saúde Pública da mesma Universidade.

(2) Do Centro de Dinâmica Populacional do Departamento de Epidemiologia da Faculdade de Medicina da USP e do Grupo de Pediatria Social da Faculdade de Medicina da USP São Paulo, S.P., Brasil. 
YUNES, J. - O ensino do contrôle da fertilidade e de problemas populacionais em escolas mécas brasileiras. Rev. Saúde pübl., S. Paulo, 4:79-84, jun. 1970.

0 processamento de dados foi realizado no Centro de Planejamento Populacio. nal da Escola de Saúde Pública da Universidade de Michigan.

\section{RESULTADOS E ANALISE}

Das 42 escolas médicas brasileiras, 22 $(52,8 \%)$ responderam os questionários enviados, proporção considerada bastante satisfatória, para um país onde êste método de pesquisa não é uma tradição. Destas Escolas, 14, ou seja, 63,6\% declararam ensinar o contrôle da fertili. dade, sendo que das 8 Escolas restantes que não ensinavam, 6 mencionaram planos de inclusão no curriculum médico em futuro próximo. Muitas delas solicitaram ao Centro de Planejamento Populacional a remessa de material e publicações sôbre o assunto. Uma das Escolas declarou ser contrária ao ensino do contrôle da fertilidade, por ser o Brasil um país de dimensôes iguais às dos Estados Unidos, mas com a metade da população dêste.

A maioria das Escolas que responderam o questionário, ou seja, 14, o fizeram através do Departamento de Obstetrícia e Gi. necologia; 4 através dos Departamentos de Obstetrícia e Ginecologia e Medicina
Preventiva concomitantemente; e, as 4 Escolas restantes, através dos Departamentos de Clínica Médica, Medicina Preventiva, Endocrinologia e combinações de todos êstes Departamentos, conforme se observa na Tabela 1.

Das 14 Escolas que ensinavam o contrôle da fertilidade, $57,5 \%$ o faziam pelo Departamento de Obstetrícia e Ginecologia; 28,5\% através dos Departamentos de Obstetrícia e Ginecologia e Medicina Preventiva concomitantemente; e, $14 \%$, respectivamente pelos Departamentos de Medicina Preventiva e Endocrinologia, de acôrdo com a Tabela 1.

\section{Indicações para o ensino do contrôle da fertilidade}

Entre os principais fatôres que justificaram o ensino do contrôle da fertilidade, as indicações por "enfermidade ou agravamento físico" e "enfermidade ou problemas psiquiátricos", foram apontados unânimemente pelas 11 escolas que responderam a êsse quesito, conforme se observa na Tabela 2. 0 "retardamento mental", a "limitação do tamanho da família" e o "stress sócio-econômico" foram apontados em 90,9\% das indicações. Seguem-se, em ordem de prioridade, as indica-

T A BELA 1

Departamentos das Escolas Médicas Brasileiras que responderam ao questionário e proporção dos que ensinavam o contrôle da fertilidade.

\begin{tabular}{|c|c|c|}
\hline Departamentos & $\begin{array}{l}\text { N.o de Escolas que responderam } \\
\text { p/Departamento }\end{array}$ & $\begin{array}{l}\text { N.o de Escolas que ensinavam } \\
\text { o contrôle da fertilidade }\end{array}$ \\
\hline Obstetricia e Genecologia & $14(64,0 \%)$ & $8(57,5 \%)$ \\
\hline Medicina Preventiva & $1 \quad(4,5 \%)$ & $1 \quad(7,0 \%)$ \\
\hline Clínica Médica & $1(4,5 \%)$ & $0 \quad(0,0 \%)$ \\
\hline $\begin{array}{l}\text { Obstetricia e Ginecologia e } \\
\text { Medic. Prevent. e Clín. Médica }\end{array}$ & $1 \quad(4,5 \%)$ & $0 \quad(0,0 \%)$ \\
\hline $\begin{array}{l}\text { Obstetricia e Ginecologia e } \\
\text { Medicina Preventiva }\end{array}$ & $4(18,0 \%)$ & $4(28,5 \%)$ \\
\hline Endocrinologia & $1 \quad(4,5 \%)$ & $1 \quad(7,0 \%)$ \\
\hline TOTAL & $22(100,0 \%)$ & $14(100,0 \%)$ \\
\hline
\end{tabular}


YUNES, J. - O ensino do contrôle da fertilidade e de problemas populacionais em escolas mécas brasileiras. Rev. Saúde públ., S. Paulo, 4:79-84, jun. 1970.

ções por "defeito genético" e "aumento do intervalo entre os nascimentos" $(81,8 \%)$; "história do abôrto provocado" $(54,6 \%)$; "prevenção de problemas conjugais" $(45,4 \%)$; "rotina em exames pós-partum" e "a simples pedido do paciente" $(36,4 \%$ e $18,2 \%$ respectivamente). Vem nos cha. mado a atenção o fato do "abôrto provocado" ser freqüentemente apontado pelos médicos como indicação prioritária para o contrôle da natalidade. No entretanto, em nossa tabulação êste achado não foi encontrado. queno conforme descreveremos adiante. No Brasil, carecemos de profissionais que tenham formação adequada em demogra. fia. Recentemente, em 1966, a Faculdade de Saúde Pública da USP, estabeleceu um convênio entre o Govêrno Brasileiro e a Organização Panamericana da Saúde, criando o Centro de Estudos de Dinậmica Populacional (CEDIP), tendo como principal objetivo o ensino e pesquisa no campo da demografia, oferecendo para isto, anualmente, cursos para profissionais graduados em ciências médicas e humanas, bem como para

TABELA 2

Indicações apontadas para o ensino do Contrôle da Fertilidade *

\begin{tabular}{|c|c|c|c|c|}
\hline \multirow{2}{*}{ Indicações } & \multicolumn{2}{|c|}{$\operatorname{Sim}$} & \multicolumn{2}{|c|}{ Não } \\
\hline & N.o & $\%$ & N.o & $\%$ \\
\hline Enfermidade ou agravamentos físicos & 11 & $100, \mathrm{C}$ & 0 & 0 \\
\hline Enfermidade ou problemas psiquiatricos & 11 & 100,0 & 0 & 0 \\
\hline Retardamento Mental & 10 & 90,9 & 1 & 91,1 \\
\hline Defeito genético & 9 & 81,8 & 2 & 18,2 \\
\hline Aumento de intervalo entre os nascimentos & 9 & 81,8 & 2 & 18,2 \\
\hline Limitação do tamanho da família & 10 & 90,9 & 1 & 9,1 \\
\hline "Stress" sócio-econômico & 10 & 90,9 & 1 & $\mathbf{9 , 1}$ \\
\hline Prevenção de problemas conjugais & 5 & 45,4 & 6 & 54,6 \\
\hline Rotina em exames de post-partum & 4 & 36,4 & 7 & 63,6 \\
\hline História de abôrto provocado & 6 & 54,6 & 5 & 45,4 \\
\hline $\begin{array}{l}\text { A simples pedido da paciente sem indica- } \\
\text { ção necessária }\end{array}$ & 3 & 18,2 & 8 & 81,8 \\
\hline Outros & 一 & - & - & - \\
\hline
\end{tabular}

(*) Percentagem baseada em 11 "escolas que ensinam o contrôle de fertilidade".

Paralelamente ao ensino do contrôle da fertilidade, $85,8 \%$ das escolas médicas, ensinavam os aspectos demográficos em âmbito local, nacional e mundial (Tabela 3). Esta constatação deve-se, provàvelmente, ao fato do problema do crescimento populacional ser um dos assuntos mais discutidos no mundo hodierno, tanto por suas implicações sociais, econômicas e políticas, como por razões de saúde pública. Presume-se que êste ensino, oferecido pelas escolas médicas, seja bem elementar, uma vez que o número de horas de aulas por ano, do curso médico, é pe- profissionais de pós-graduação em saúde pública.

\section{TA B E L A 3}

Ensino dos aspectos demográficos em âmbito local, nacional e mundial, paralelamente ao ensino do contrôle de fertilidade.

\begin{tabular}{l|r|r}
\hline Tipo de respostas & N.o & $\%$ \\
\hline Sim & 12 & 85,8 \\
Não & 1 & 7,1 \\
Não declarado & 1 & 7,1 \\
\hline TOTAL & 14 & 100,0 \\
\hline
\end{tabular}


YUNES, J. - 0 ensino do contrôle da fertilidade e de problemas populacionais em escolas mécas brasileiras. Rev. Saúde públ., S. Paulo, 4:79-84, Jun. 1970.

\section{Métodos de contrôle de fertilidode ensinados}

Classificamos o estudo dos métodos ensinados como preferidos, aprovados e não preferidos, desaprovados, não discutidos e não mencionados (Tabela 4). Entre os métodos preferidos, $66,7 \%$ das Escolas ensinavam o uso das pílulas anovulatórias, $58,1 \%$ o método do rítmo ou Ogino-Knauss, 33,3\% o dos dispositivos intrauterinos e preservativo. Os outros métodos eram ensinados em menos de $16,6 \%$ das escolas médicas e entre êles destacaram-se o diafragma, geléias, duchas pós-coito, tabletes espumantes, cremes, interrupções do coito, supositórios e esponjas. Mais de $50 \%$ das Escolas desaprovaram a interrupção do coito e a ducha pós-coito como método de ensino. Entre os métodos que menos se discutia destacaram-se, em cêrca de $30 \%$ das Escolas, os supositórios, esponjas e tabletes espumantes. A proporção de outros métodos ensinados de acôrdo com a preferência pode ser observada com maiores detalhes na Tabela 4 .
Chamou-nos a atenção a proporção de escolas médicas $(58,1 \%)$ que preferem o método do rítmo para ensino, tendo $33,3 \%$ aprovado êste método - mas não era o preferido - e sòmente uma escola desaprovado. Entre as variantes do método do rítmo ensinado estudou-se o método do calendário, da temperatura basal e do teste da glicose; das escolas que ensinavam o método do calendário, $50 \%$ o consideraram preferido e $20 \%$ aprovado e não preferido (Tabela 5). 0 restante das Escolas não discutiram ou não mencionaram esta variante. Das que ensinavam o método da temperatura basal como método do rítmo, $60 \%$ o consideraram como preferido e sòmente $10 \%$ o aprovaram mas não o preferiram. As demais Escolas desaprovaram ou não mencionaram esta varian. te do método. Nenhuma delas preferiu o teste da glicose como método do rítimo, sendo que $60 \%$ não o mencionaram como variante do método, $30 \%$ não o discutiram e $10 \%$ o desaprovaram.

TA B ELA 4

Métodos de contrôle de fertilldade ensinados *

\begin{tabular}{|c|c|c|c|c|c|c|c|c|c|c|}
\hline \multirow{2}{*}{ Métodos ensinados } & \multicolumn{2}{|c|}{ Preferidos } & \multicolumn{2}{|c|}{$\begin{array}{c}\text { Aprovados } \\
\text { n/ preferidos }\end{array}$} & \multicolumn{2}{|c|}{$\begin{array}{c}\text { Desaprova- } \\
\text { dos }\end{array}$} & \multicolumn{2}{|c|}{$\begin{array}{l}\text { Não dis- } \\
\text { cutidos }\end{array}$} & \multicolumn{2}{|c|}{$\begin{array}{l}\text { Não men- } \\
\text { cionados }\end{array}$} \\
\hline & $\%$ & N.o & $\%$ & N.O & $\%$ & N.o & $\%$ & N.o & $\%$ & N.o \\
\hline Ritmo & 7 & 58,1 & 4 & $\mathbf{3 3 , 3}$ & 1 & 8,6 & - & - & - & - \\
\hline Pilulas anovulatórias & 8 & 66,7 & 4 & 33,3 & - & - & - & 一 & 一 & - \\
\hline Dispositivos Intrauterinos & 4 & $\mathbf{3 3 , 3}$ & 4 & $\mathbf{3 3 , 3}$ & $\mathbf{3}$ & 25,0 & 1 & 8,4 & - & - \\
\hline Interrupcão do coito & 1 & 8,4 & 2 & 16,6 & 6 & 50,0 & 1 & 8,4 & 2 & 16,6 \\
\hline Preservativo & 4 & $\mathbf{3 3 , 3}$ & 4 & 33,3 & 3 & 25,0 & 1 & 8,4 & 一 & - \\
\hline Diafragma & 2 & 16,6 & 8 & 66,8 & 2 & 16,6 & - & - & - & - \\
\hline Geléias & 2 & 16,6 & 5 & 41,7 & 4 & 33,3 & 1 & 8,4 & 一 & 一 \\
\hline Duchas pós-coito & 2 & 16,6 & 2 & 16,6 & 7 & $\mathbf{5 8 , 4}$ & 1 & 8,4 & - & - \\
\hline Supositórios & 1 & 8,4 & 2 & 16,6 & 4 & 33,3 & 4 & 33,3 & 1 & 8,4 \\
\hline Esponjas & 1 & 8,4 & 1 & 8,4 & 5 & 41,5 & 4 & $\mathbf{3 3 , 3}$ & 1 & $\mathbf{8 , 4}$ \\
\hline Tabletes espumantes & 2 & 16,6 & 2 & 16,6 & 4 & 33,4 & 4 & $\mathbf{3 3 , 4}$ & 一 & - \\
\hline Cremes & 2 & 16,6 & 4 & 33,4 & 4 & $\mathbf{3 3 , 4}$ & 2 & 16,6 & - & - \\
\hline Outros & 一 & 一 & - & 一 & 一 & - & - & - & 一 & 一 \\
\hline
\end{tabular}

(*) Percentagem baseada em 12 "escolas que ensinam o contróle de fertilidade". 
YUNES, J. - O ensino do contrôle da fertilidade e de problemas populacionais em escolas mécas brasileiras. Rev. Saúde públ., S. Paulo, 4:79-84, jun. 1970.

TA B ELA 5

Variantes do método do rítmo ensinadas *

\begin{tabular}{|c|c|c|c|c|c|c|c|c|c|c|}
\hline \multirow{2}{*}{ Variantes } & \multicolumn{2}{|c|}{ Preferidas } & \multicolumn{2}{|c|}{$\begin{array}{l}\text { Aprovadas } \\
\mathbf{n} / \text { preferidas }\end{array}$} & \multicolumn{2}{|c|}{$\begin{array}{l}\text { Desapro- } \\
\text { vadas }\end{array}$} & \multicolumn{2}{|c|}{$\begin{array}{l}\text { Não dis- } \\
\text { cutidas }\end{array}$} & \multicolumn{2}{|c|}{$\begin{array}{l}\text { Não men- } \\
\text { cionadas }\end{array}$} \\
\hline & N.o & $\%$ & N.o & $\%$ & N.O & $\%$ & N.o & $\%$ & N.o & $\%$ \\
\hline Método do Calendário & $\mathbf{5}$ & 50,0 & 2 & 20,0 & 0 & 0 & 1 & 10,0 & 2 & 20,0 \\
\hline Temperatura Basal & 6 & 60,0 & 1 & 10,0 & 1 & 10,0 & - & 一 & 2 & 20,0 \\
\hline Teste de Glicose & 一 & - & 一 & 一 & 1 & 10,0 & 3 & 30,0 & 6 & 60,0 \\
\hline
\end{tabular}

(*) Percentagem baseada em 10 "escolas que ensinam o contrôle de fertilidade".

Métodos pedagógicos utilizados e presença de clinicas de planejamento familiar para o ensino dos estudantes de medicina

A maioria das escolas, ou seja, $71,4 \%$ -ensinavam o contrôle da fertilidade através de aulas teóricas ou seminários e sòmente $28,6 \%$ utilizavam-se de pacientes ou de recursos audio-visuais. Das escolas médicas que ensinavam o contrôle da fertilidade, $10(71,4 \%)$ não dispunham de clínica de planejamento familiar e 4 $(28,6 \%)$ possuiam clínicas em hospitais filiados às Escolas. Durante a época da pesquisa, 3 Escolas declararam que instalariam clínicas de planejamento familiar.
Número de horas destinado ao ensino de contrôle da fertilidade nos diversos anos do curso médico

0 ensino do contrôle da fertilidade, quer através de aulas e demonstrações ou de práticas clínicas era ministrado desde o $2 .^{\circ}$ ao $5 .^{\circ}$ ano do curso médico, estando concentrado geralmente neste último ano, conforme se observa na Tabela 6. Uma das escolas ensinava a matéria em dois anos do curso, ou seja, no $4 .^{\circ}$ e $5 .^{\circ}$ ano; outra ensinava durante quatro anos, isto é, do $2 .^{\circ}$ ao $5 .^{\circ}$ ano; as restantes ensinavam sòmente em um dos anos do curso mé. dico. Em relação ao número de horas para aulas e demonstrações teóricas, as

TABELA 6

Distribuição de horas dispendidas no ensino de contrôle de fertilidade.

\begin{tabular}{c|c|c|c|c|c|c}
\hline \multirow{2}{*}{ Ano } & \multicolumn{3}{|c|}{ Aulas e/ou Demonstracão } & \multicolumn{4}{c}{ Prática Clínica } \\
\cline { 2 - 7 } & $\begin{array}{c}\text { N.0 de* } \\
\text { escolas }\end{array}$ & $\begin{array}{c}\text { Médias } \\
\text { horas/ano }\end{array}$ & Amplitude & $\begin{array}{c}\text { N.o de * } \\
\text { escolas }\end{array}$ & $\begin{array}{c}\text { Médias } \\
\text { horas/ano }\end{array}$ & Amplitude \\
\hline 1.0 & - & - & - & - & - & - \\
2.0 & 1 & 4 & 4 & 1 & 10 & 10 \\
3.0 & 1 & 4 & 4 & 1 & 10 & 10 \\
4.0 & 4 & 9,3 & $3-21$ & 2 & 6 & 2 \\
5.0 & 8 & 3,5 & $1-10$ & 2 & -10 \\
6.0 & - & - & - & - & - & 2 \\
\hline
\end{tabular}

(*) Cálculo baseado em 10 "escolas que ensinam o contrôle da fertilidade. 
YUNES, J. - O ensino do contrôle da fertilidade e de problemas populacionais em escolas mécas brasileiras. Rev. Saúde públ., S. Paulo, 4:79-84, jun. 1970.

Escolas destinavam de 1 a 21 horas anuais encontrando-se maior número no $40^{\circ}$ ano onde as escolas, no seu conjunto, dispendiam em média 9,3 horas por ano. Para a prática clínica, o número de horas anuais variou de 2 a 10 horas. A maioria das escolas, ou seja, $80 \%$ não dedicavam nenhum tempo para prática clínica. Conforme se observa na Tabela 7, das 14 Escolas que ensinavam o contrôle da fertilidade, $50,0 \%$ não examinavam os alunos nesta matéria, enquando que $42,8 \%$ o faziam.

TABELA 7

Exames sobre a matéria "contrôle da fertilidade"

\begin{tabular}{l|r|r}
\hline Tipos de respostas & N.o & $\%$ \\
\hline Sim & 6 & 42,8 \\
Não & 7 & 50,0 \\
Não declarado & 1 & 7,2 \\
\hline TOTAL & 14 & 100,0 \\
\hline
\end{tabular}

YUNES, J. - [The teaching of fertility and population problems at Brazilian schools of medicine]. Rev. Sauide puibl., S. Paulo, 4:79-84, jun. 1970.

SUMMARY - A survey of teaching about fertility regulation and population problems in the 42 medical schools of Brazil was carried out in 1967. Fertility regulation was taught in 14 of the 22 schools: which replied, and 6 expressed intention to start such teaching. Interest in demography and social aspects was higher, and great emphasis was placed on giving contraceptive help for "physical illnes" or "impairment" and "phychiatric problems". Availability of clinical facilities for teaching students to give contraceptive services: was generally low. Pill and the rythm method were the preferred contraceptive. for teaching medical students.

\section{REFERENCIAS BIBLIOGRAFICAS}

1. ELIOT, J. W. \& HAUSER, C. - The teaching of human reproduction, sexuallty and family planning in 26 Middle North American medical schools. In: MACY FOUNDATION CONFERENCE ON TEACHING FAMILY PLANNING IN MEDICAL SCHOOLS, 4th, Ann Arbor, Mich., 1968.

2. ELIOT, J. W.; VILLADIEGO, F. \& YUNES, J. - Instruction in fertility regulation in medical schools of Latin America. J. med. Educ., 44:1044-50, Nov. 1960.

3. PAN AMERICAN HEALTH ORGANIZATION. Directory of schools of medicine in Latin America, 1966. Washington, Medical Information Center, 1967.

4. TIETZE, C. et al. - Teaching of fertility regulation in medical schools: survey in the United States and Canadá, 1964. J. Amer. med. Assoc., 196:20-4, Apr. 1966. 